\title{
International patients on operation vacation - perspectives of patients travelling to Hungary for orthopaedic treatments
}

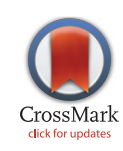

\author{
Eszter Kovacs $^{1, *}$, Gabor Szocska ${ }^{1}$, Cécile Knai ${ }^{2}$
}

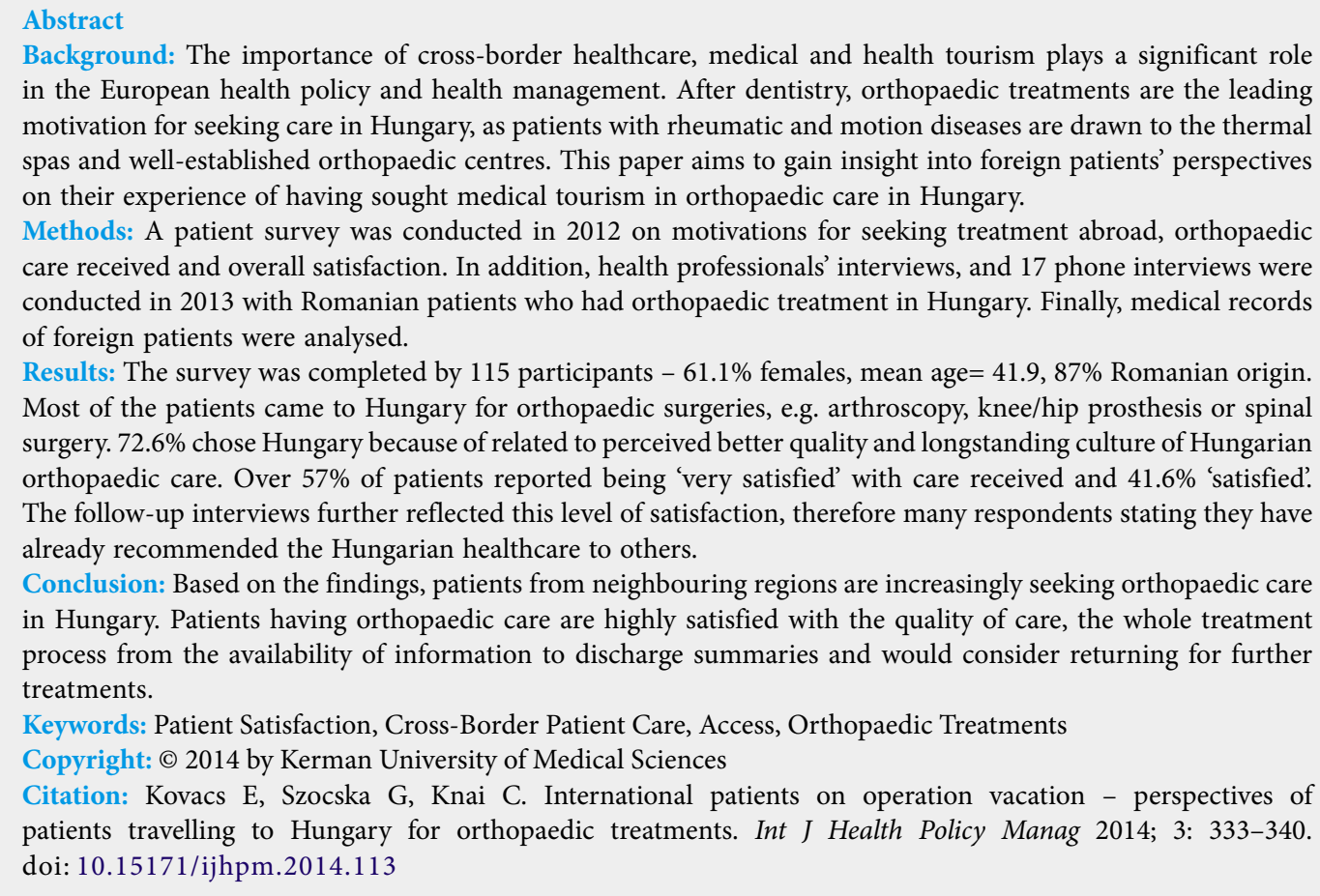

Background: The importance of cross-border healthcare, medical and health tourism plays a significant role in the European health policy and health management. After dentistry, orthopaedic treatments are the leading motivation for seeking care in Hungary, as patients with rheumatic and motion diseases are drawn to the thermal spas and well-established orthopaedic centres. This paper aims to gain insight into foreign patients' perspectives on their experience of having sought medical tourism in orthopaedic care in Hungary.

Methods: A patient survey was conducted in 2012 on motivations for seeking treatment abroad, orthopaedic care received and overall satisfaction. In addition, health professionals' interviews, and 17 phone interviews were conducted in 2013 with Romanian patients who had orthopaedic treatment in Hungary. Finally, medical records of foreign patients were analysed.

Results: The survey was completed by 115 participants $-61.1 \%$ females, mean age $=41.9,87 \%$ Romanian origin. Most of the patients came to Hungary for orthopaedic surgeries, e.g. arthroscopy, knee/hip prosthesis or spinal surgery. $72.6 \%$ chose Hungary because of related to perceived better quality and longstanding culture of Hungarian orthopaedic care. Over $57 \%$ of patients reported being 'very satisfied' with care received and $41.6 \%$ 'satisfied'. The follow-up interviews further reflected this level of satisfaction, therefore many respondents stating they have already recommended the Hungarian healthcare to others.

Conclusion: Based on the findings, patients from neighbouring regions are increasingly seeking orthopaedic care in Hungary. Patients having orthopaedic care are highly satisfied with the quality of care, the whole treatment process from the availability of information to discharge summaries and would consider returning for further treatments.

Keywords: Patient Satisfaction, Cross-Border Patient Care, Access, Orthopaedic Treatments Copyright: (c) 2014 by Kerman University of Medical Sciences

Citation: Kovacs E, Szocska G, Knai C. International patients on operation vacation - perspectives of patients travelling to Hungary for orthopaedic treatments. Int J Health Policy Manag 2014; 3: 333-340. doi: $10.15171 /$ ijhpm.2014.113

Article History:

Received: 29 July 2014

Accepted: 28 October 2014

ePublished: 30 October 2014

\section{Key Messages}

Implications for policy makers

- Protecting patients' rights and quality healthcare by facilitating research and analysis in cross-border healthcare

- Facilitating access to healthcare abroad by revealing existing patient pathways, bi- and multilateral agreements in different specialty fields, e.g. in orthopaedic care

- Providing transparency in information access and continuity of care to make informed-choice

Implications for public

Patients might face several barriers in seeking healthcare in their country of origin, e.g. long waiting lists, non-available treatments or lack of required technology. The European Union (EU) legislation clarifies rules on access to healthcare in another country by providing the framework of patients' rights within the EU. Previous patient experiences showed that patients benefit quick and easy access to quality care in orthopaedics when choosing Hungary. Patient reports indicated high satisfaction levels, even in case of high risk elective surgery where patients take the elevated risk of the long distance travelling and the challenges of cross-border healthcare.

\section{Introduction}

Medical and health tourism are rapidly growing sectors resulting in increasing patient mobility across borders (1-8). A 2007 Flash Eurobarometer survey of 27,200 individuals 15 years or over across all European Union (EU) member states estimated that approximately $4 \%$ of Europeans received medical treatment in another EU member state during the year prior to the survey (2). Moreover his study indicated that over $54 \%$ of EU citizens would be willing to travel abroad for medical care (2). National estimates also suggest that medical tourism is an important sector. For example Connell estimated that about 50,000 people left the UK in 2003 as medical tourists (9), another estimation showed that this number increased to 100,000 in 2009 (10). The number of Americans travelling overseas was predicted between 50,000 and 500,000 (11). As contemporary literature represents, predictions but 
no precise data is available yet on cross-border healthcare.

The terms "medical tourism" and "health tourism" are used quite widely and sometimes are vague. While health and medical tourism could be differentiated on the seriousness of illness and disease and the consequent level of physical and surgical intervention required, both forms of treatment involve crossing the border to seek care in another country, as explained in Box 1. Therefore, these definitions are often used interchangeably $(1,5,7,9,12,13)$. In general, we highlight that medical tourism refers to treatments or surgeries planned in advance, which take place outside a patient's usual place of residence.

Additionally, due to Hungary's excellent tradition of thermal baths and spas, balneology is playing a significant role in healthcare, particularly in orthopaedic care. Several treatments can be complemented with balneotherapy, hydrotherapy, physiotherapy and natural medicinal products. In the process of medical wellness doctors often offer patients some of these options in the interest of holistic patient care $(14,15)$.

\section{Policy foundations}

Since 1998 each European citizen has had the right to seek services and treatments within the EU. This is grounded in the core principles of freedom of movement across the EU $(7,18,19)$ and now further clarified with the adoption of the 2011/24/EU Directive of the European Parliament and of the

\section{Box 1. Definitions}

Patient mobility: Movement of patients, referred when cross-border collaboration involves the transfer, movement or exchange of patients from one system or one provider to another (7).

Cross-border healthcare: crossing the border in order to obtain healthcare and medical services, cross-border purchasing of health services and products (7), typically sought in countries within the same region (10).

- Health tourism: the organised travel outside one's local environment for the maintenance, enhancement or restoration of an individual's well-being in mind and body $(5,12)$; travel where the primary purpose is treatment in pursuit of better health, any pleasure-orientated tourism which involves an element of stress relief (16).

Medical tourism: travel abroad with the intention of obtaining non-emergency medical services; consumers elect to travel across borders or to overseas destinations to receive their treatment $(5,12)$; refers to treatments or surgery that have been planned in advance to take place outside a patient's usual place of residence (1); travel for the purpose of delivering healthcare or travel for the purpose of seeking healthcare (17); the practice of travelling to another country with the purpose of obtaining healthcare (14).

Medical wellness: a combination of medical and health tourism, with wellness' benefits; combine medical services with wellness offerings, therefore representing a possible synergy between the two markets (14). Wellness/Spa tourism refers to visiting spas, homeopathy treatments or traditional therapies (16), relaxation treatments (1).
Council of 9 March 2011 on the application of patients' rights in cross-border healthcare (20).

The debate about cross-border healthcare arose from several cases in the last two decades and mainly centred on authorisation and reimbursement issues (e.g. Decker-Kohll, Vanbraeckel, Smith-Peerbooms) at the European Court of Justice $(18,19)$. In addition, the introduction of the European Health Insurance Card in 2004 raised the opportunity in easy access to health services in EU member states.

The aforementioned processes facilitated the consultation on the conditions and ruling of cross-border care, and the preparatory work on establishing an EU directive concerning the right of patients to benefit from medical treatment in another member state. The first draft of the Directive on patients' rights was prepared in 2008, following which the Directive was renegotiated over a period of two and a half years, resulting in a revised draft agreed in December 2010. This was voted on in January 2011, ratified by the Council in February 2011 and became law on April $4^{\text {th }} 2011$. The member states implemented the Directive into national legislation in October 2013.

These factors of the European legislative framework greatly contributed to patient mobility. With this legislation each European citizen has the right to receive healthcare (be it planned and unplanned) in any EU member states. Since the Directive focuses on several aspects of patients' rights, the most recent changes will be seen in the near future. Additionally, the Directive aims to clarify crucial points about cross-border healthcare, i.e. cost of care, reimbursement, patient safety, complaints, national contact points etc. Using this information, patients have the opportunity to gain more information directly from the member state in which they intend to receive healthcare. Indeed, the process of crossborder care becomes more transparent and patient mobility might be monitored more closely.

The opportunity for medical tourism has resulted in increased patient mobility. Typologies explaining the motivations and types of individuals crossing borders for healthcare have been proposed: 1) there are temporary visitors abroad, 2) people living in border regions, or 3) elderly retiring to other countries, 4) people sent abroad by their doctors and 5) people going abroad on their own initiative $(7,19-21)$.

\section{Objectives}

Previous studies have sought to understand the motivation for seeking medical treatment abroad, and foreign patient satisfaction rates with Hungarian healthcare (3,4,22-25). Based on these studies the key motivations include the good cost/benefit ratio (affordable prices), good quality of care, the possibility of combining treatment with holidays, high accessibility, availability of special or joint treatments, high level of trust and pleasant previous treatment experiences $(10,15,22-24)$.

As widely known, many patients seek dental care in Hungary - mostly in private provision - (22-25), but nowadays other fields started gaining more attention, such as orthopaedic care $(6,15)$. Cross-border healthcare tends to attract people first from neighbouring regions and nevertheless patients 
travelling from longer distances. Thus, this paper focuses on people travelling to Hungary to receive planned treatments, and particularly people living in border regions, the majority of which are Romanian patients. Specifically it explores the patients' experience of travelling to Hungary to receive orthopaedic treatment, their motivation for doing so and their satisfaction with healthcare received whilst in Hungary.

\section{Methods}

In order to gain insight into the experience of patients, triangulation of data collection methods was used, including a survey disseminated to foreign patients arriving to Hungary for healthcare, secondary analysis of medical records, and follow-up phone interviews with a selection of patients having completed the survey.

A patient survey on the motivations for treatment abroad, orthopaedic care and satisfaction was designed to capture the following themes: 1) the decision to have treatment in Hungary, including choice for combinations or types of treatments; 2) the process of organising treatment abroad, including gaining information about the foreign provider, availability and accessibility of care, prices compared to the home country; 3) the satisfaction with treatment abroad including the patients' level of trust in the foreign provider, communication with healthcare staff, difficulties and advantages of treatment abroad; and 4) experiences with discharge and aftercare. The 25-item survey took approximately 20 minutes to complete (see Appendix 1). The final version of the survey was disseminated on 2 March 2012 in Hungarian, Romanian and English. We distributed the questionnaires in three orthopaedic clinics' waiting rooms and patient information desks. Data collection lasted six months, starting in August 2012.

\section{Selection of clinics}

Eight individual and five focus group interviews were conducted (in January-February 2012) to gain deeper insight to patient mobility in orthopaedic care, revealing the aspects of health professionals. Clinics were selected based on opinions of representatives and leaders of professional bodies and national institutes of orthopaedics, who indicated cross-border care in orthopaedics in a significant volume, particularly among Romanian patients. The location of hospitals also provided opportunity to test the presence of foreign patients: 2 of the 3 hospitals are situated close to Romanian-Hungarian border, and the third hospital in the capital represents higher level access for foreign patients. In the second step we confirmed by focus group interviews with health professionals-staff of the selected clinics-the presence and significance of treatment of foreign, particularly Romanian patients. The three clinics were suggested by representatives of national professional bodies, and the rate of foreign patients was confirmed by hospital staff around $4 \%-10 \%$, that is, 150 patients in in-patient care annually. Secondly, we conducted an analysis of medical records and discharge summaries of foreign patients accessed in hospitals that were checked for numbers of monthly/annual treatments in the unit and the content of discharge summaries was also analysed [Hospital Discharge - $c f$. Organisation for Economic Co-operation and Development (OECD) Indicators and (26)]. Data protection and confidentiality was ensured by anonymous and summarised tables created by the hospitals for research purposes.

Finally, in January 2013, we conducted follow-up phone interviews $(\mathrm{N}=17)$ with Romanian patients who had orthopaedic treatment in Hungary in the year 2012. These patients were selected from the questionnaire survey respondents, those who provided their contact details for further research purposes. In total 24 people provided contact details in the questionnaire and 17 people were available for the interviews. The aim of the follow-up interviews was to gain a more in-depth understanding of their experience, including their level of satisfaction with the treatment in Hungary and reasons why, as well as an understanding of how they were planning the next steps (including further treatment abroad) and whether they would recommend treatment abroad to others. The time-lag between the questionnaire survey and the follow-up interviews was set in order to leave enough time for patients to terminate their ongoing treatment processes.

\section{Results}

In all, 115 individuals completed the questionnaire survey: $61.1 \%$ were females, mean age $=41.9, \mathrm{SD}=17.1,87 \%$ with Romanian origin (Table 1). The remaining respondents came from various countries: Libya, Germany, Serbia, Ireland, Slovakia, Slovenia, Spain, the UK and the US.

\section{Treatment}

The majority (58.4\%) of respondents stated having treatment in Hungary for the first time. A further $24.8 \%$ came to Hungary for the second time and $16.8 \%$ reported having had sought treatment abroad on several occasions and not exclusively in Hungary. Most of the patients reported coming to Hungary for orthopaedic surgeries, including arthroscopy, knee prosthesis, hip replacement or spinal surgery. Most (78.2\%) came for a single treatment while the rest had multiple treatments. Patients from Romanian origin tend to have more multiple treatments compared to the non-Romanian patients ( $25 \%$ vs. $0 \%$ respectively $P<0.050$ ). The follow-up interviews emphasised that patients had good experiences whilst in Hungary and that the benefits of care received continued since returning to their home country. Fifteen respondents declared that based on the good experiences they would choose to return to Hungary for further treatments. As noted by two interviewees: "I would consider returning for further

\begin{tabular}{ll} 
Table 1. Self-reported socio-demographic characteristics of respondents \\
\hline Gender & $61.1 \%$ females, 38.9\% males \\
\hline Age & Mean age $=41.9$ years (SD=17.1) \\
& $87 \%$ with Romanian origin, $2.6 \%$ Libya, $1.7 \%$ \\
& Germany, 1.7\% Serbia, $0.9 \%$ Slovakia, $0.9 \%$ \\
Country of origin & Slovenia, 0.9\% Spain, 0.9\% Ireland, 0.9\% UK, \\
& $0.9 \%$ USA \\
Social status & $4.3 \%$ Lower class, 83\% Middle class, 12.8\% \\
& Upper class
\end{tabular}

Note: Country of origin was recoded to Romanian and non-Romanian groups for further analysis 
treatments but financial conditions count a lot". Seven patients stated that they still need to return sometimes for additional consultations. Similarly to them, eight patients said that "I would definitely come back if any need emerges".

\section{The process}

The majority (93.6\%) planned the treatment on their own without the support of any agencies, while only $3.7 \%$ organised their care via a medical tourism agency and $2.8 \%$ by a travel agency. The majority of the responses indicate that very few medical tourism or travel agencies are supporting the arrangement of the trip $(97.7 \%$ of Romanian and $61.5 \%$ of non-Romanian patients organise the trip themselves). On average they travelled $390 \mathrm{~km}(\mathrm{SD}=889 \mathrm{~km})$, where Romanians travelled significantly lower distances than nonRomanian nationals $(P<0.010)$. In terms of the information sources used, friends are the most common source from whom patients gain information about treatment abroad (Table 2). The majority of Romanian patients (63.6\%) arrived to Hungary based on recommendations of friends, on the other hand, $69.2 \%$ of non-Romanian patients decided to have treatment in Hungary based on doctors' recommendations $(P<0.001)$. As the follow-up interviews indicated, upon returning home patients tended to recommend treatment in Hungary and/or the specific hospital units to their friends and seven patients knew others seeking care in Hungary based on their recommendations. As noted by an interviewee: "Based on my good experiences I have already recommended the Hungarian orthopaedics [services] to my relatives, friends and acquaintances". Another interviewee reported knowing: "[...] at least ten people who already went to Hungary for healthcare on my recommendations". Finally patients emphasised that it was very easy $(57.1 \%)$ and easy enough $(40.2 \%)$ to get appointment for their treatment abroad - regardless their country of origin.

\section{Motivations}

When considering the main general advantages of treatment abroad, the majority (58.7\%) of respondents reported being motivated by their belief that healthcare of a different country would provide them with greater quality of healthcare compared to their home country. Secondly, 34.9\% reported being motivated by higher accessibility and $6.4 \%$ by the availability of special or joint/multiple treatments indicating lack of suitable options at home (Figure 1).

We also asked respondents about the reasons why did they choose Hungary in receiving healthcare (Figure 2). The great majority of the patients reported seeking care in Hungary because of better quality (72.6\%). The second main motivation is the availability of special treatments that

Table 2. Sources of information about hospitals and treatment abroad

\begin{tabular}{ll}
\hline & $\%$ \\
\hline Friends & 57.9 \\
Doctors from home country & 27.2 \\
Internet & 13.2 \\
Other: TV, Insurer & 1.7 \\
\hline
\end{tabular}

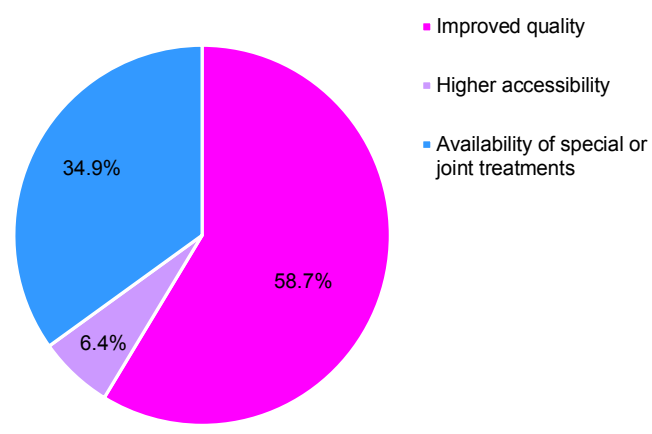

Figure 1. Advantages of treatment abroad

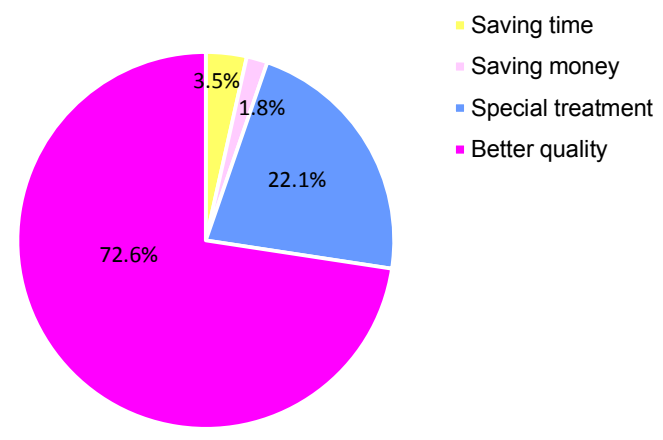

Figure 2. Reasons for choosing Hungary

might not be available in the patients' home country (22.1\%). The third key driver was saving time, namely, quick access (3.5\%). Finally, only $1.8 \%$ indicated "saving money" as main motivation for treatment in Hungary. Statistical analysis confirmed that Romanian patients and non-Romanian origin patients show significant differences in motivations, namely "better quality" is more important to Romanians (79.6\% vs. $23.1 \%$ ) and "special treatment" is more important to nonRomanians (15.3\% vs. $69.2 \%$ ). Comparing the prices of the treatment $65.7 \%$ declared that prices are similar in their home country, thus, saving money is not the main motivation. On the other hand, $34.3 \%$ noted some savings due to treatment abroad. Patients from neighbouring countries, $71.4 \%$ of Romanian patients, Serbian and Slovakian patients said that there they did not experience differences in prices. $28.6 \%$ of Romanian origin patients confirmed saving money, while $83.3 \%$ of the group of non-Romanian origin patients could save money $(P<0.001)$. Thus, people from neighbouring countries experience similar prices, while patients from longer distances, e.g. UK and USA see the affordable prices.

\section{Satisfaction with treatment abroad}

Patients reported being mostly satisfied (64\% was very satisfied and $35.1 \%$ satisfied) with the information provided whilst in hospital. The follow-up interviews underlined patients' great satisfaction with being treated in Hungary, with one interviewee reporting that: "the professor explained everything in a very detailed way. The information sharing was surprisingly comforting and full of respect and good behaviour". Similar rates were found when examining the overall satisfaction rates with whole treatment process in Hungary (Figure 3 ). The overall satisfaction with patient care was 


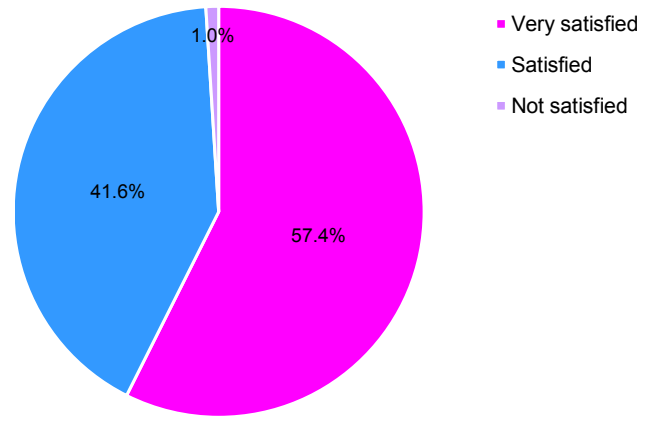

Figure 3. Overall satisfaction with treatment process

rather high 99\%, 57.4\% was very satisfied with the treatment process and $41.6 \%$ satisfied, while only one patient was not satisfied with the treatment process.

The results would indicate that patients coming to Hungary for orthopaedic treatment generally trust Hungarian providers, with $74.1 \%$ reporting a high level of trust in their foreign provider, and $25.9 \%$, a medium level trust.

Communication with health professionals was associated with reported levels of trust in health professionals. Patients' responses stated that communication with healthcare professionals was rated high, 56.3\% indicated excellent communication and $42.9 \%$ good communication flow. Indeed, a surprising fact that $47.4 \%$ is the rate of communication between Hungarian doctors and doctors in the patients' home country. As noted by an interviewee: "The Hungarian doctor paid attention [throughout] the whole treatment process, whilst continuously consulting with the Romanian doctors at home". It is helpful that several Hungarian health professionals and support staff speak Romanian, English and German. No significant differences could be detected by country of origin in satisfaction, trust or communication.

Respondents were asked to explain whether they had come across any difficulties during their treatment abroad. Nearly half $(44.6 \%)$ of patients reported no difficulties during treatment abroad, however $31.3 \%$ reported incurring unforeseen expenses, $12.5 \%$ experienced unexpected or additional exhaustion and $8 \%$ misunderstandings. A small proportion of patients $(3.6 \%)$ reported facing sociocultural problems (e.g. stemming from cultural differences such as nutrition or religion). This small percentage could be due to the fact that these patients mainly come from the bordering region where historical ties and common values might be present.

As noted by an interviewee: "There occurred one delay in my treatment process, the surgery was postponed due to my allergy, so I had to return one more time few months later that was unexpected". The majority of respondents of the follow-up interview said that they did not experience any difficulties of their treatment in Hungary: "The Hungarian staff was extremely kind and caring, they asked me two times every day about how I feel. Everything was perfect, I can say only positive things".

The main difficulties were "extra expenses" for Romanians (35.1\%) and "exhaustion" for non-Romanians (30.8\%). On the other hand, $46.6 \%$ of Romanian origin patients experienced no difficulties, this rate was $30.8 \%$ among non-Romanian origin patients $(P<0.001)$.

Discharge and aftercare - continuity of care

Every patient received a discharge summary upon being released from hospital. The majority were in Hungarian but 20.2\% received it in Romanian and 15.4\% in English. Providing an English language summary is quite common when treating foreign patients, however the Hungarian national legislation requires patient documentation solely in Hungarian (section 136-137 of 1997 Act on Healthcare and the Hungarian Healthcare Standards 2000). 65.7\% of Romanian patients received their discharge summary in Hungarian, while 53.8\% of non-Romanian patients in English. Patient documentation in Hungary consists of the following parts: personal data, nationality, diagnoses, treatment, hospital course, suggestions, control, and list of examinations, signatures of the hospital leader, unit leader and the medical specialist who had provided the care. Therefore, later on patients can provide their documents in their home county if needed. It is also worth mentioning that $40.6 \%$ of the respondents reported no need of aftercare, and almost the same volume received aftercare in their home country (39.6\%).

\section{Discussion}

Patient mobility is receiving wider attention in European health policy and health management $(4,7,8,18,19,21)$. The EU directive on patients' rights may result in patient mobility increasing in the future, since the application of authorisation and reimbursement principles entered into national legislation of Member States in October 2013 (20). The findings of this study showed that there is existing patient mobility from border regions to seek healthcare in orthopaedics care in Hungary. The volume of foreign patients is still moderate, but shows stable significance.

The aim of the present paper was to provide insight into the experience of foreign patients coming to Hungary for orthopaedic care (15). The main circumstances of treatment abroad were analysed by a questionnaire survey, secondary analysis of medical records and discharge summaries, and interviews with professionals, and follow-up interviews with patients having had treatments in Hungary. The results showed that most of the patients arrived to Hungary for orthopaedic elective surgeries, such as arthroscopy, knee prosthesis, hip replacement or spinal surgery. Most of the patients had one single treatment, one elective surgery that might require more consultations; however for few patientsmostly for Romanians-joint/multiple treatments were supplied. The findings showed that for many people this was the first occasion having treatment abroad, but one part of the respondents already had previous treatment experiences. Of the reasons for choosing Hungary in treatment abroad better quality of care played a significant role, with $72.6 \%$ arrived to Hungary because of perceived better quality of orthopaedic care. Most of the patients made their decisions of having orthopaedic treatments based on friends' recommendations and their good experiences so they have already recommended treatments in Hungary. Therefore, 
word-of-mouth still counts as a significant key driver in treatment abroad (23-25). The overall satisfaction with patient care was rather high, that is, high level satisfaction rates with information provided, with the treatment itself and health outcomes and the level of trust, further the good communication flow was even appreciated by all foreign patients. The follow-up interviews strengthened this satisfaction level. Respondents stated that due to their high level satisfaction they have already recommended the Hungarian healthcare for others, particularly orthopaedic care, however other fields of healthcare have been suggested too. Regarding discharge summaries we may state that the documentation they receive at the end of their treatment in Hungary can be used abroad providing continuity of care (26), since language barriers do not play a significant role and the content might be coherent with a standardised, harmonised EU-wide discharge summary (26).

The study has strengths and limitations. The main strength is the attempt to reveal a highly under-investigated topic, namely, cross-border orthopaedic care for patients coming from bordering regions into Hungary. Previous studies conducted in the topic of cross-border healthcare often use predictions about the patterns of treatment abroad and tend to explore the general motivational factors in patients mobility. The present research might emphasise the factors playing role in treatment abroad of Romanian patients. Secondly, triangulation in methods might increase the validity of the findings, namely, conducting quantitative and qualitative research methodology in the same time. One of the main limitations is that fact that these data are not representative of cross-border care as a whole. The study did not aim to have a representative sample of Romanian patients but attempted to capture those border regions where the presence of Romanian patients in orthopaedic care is the highest. Moreover, the questionnaire survey was voluntary and anonymous, thus self-assessment was used. Finally, due to the small number of other country of origin, comparison of the results should be considered cautiously, while the results on the attitudes of Romanian patients might be less biased.

\section{Conclusion}

The explanation of the increasing volume of patients receiving treatment abroad may be that there are gaps in perceived quality in care in patients' countries of origin. The improved quality in Hungarian healthcare attracts several patients regardless the price of treatments that is very similar in the countries of the bordering region according to the responses. Patients tend to mobilise themselves within available distances, where they are not likely to face socio-cultural problems. Thus, one of the main key drivers in medical tourism, namely, savings and cost-effective care is not the most dominant one in orthopaedic care pathways, since patients particularly from neighbouring countries do not cross the border in order to save money. The high availability and accessibility of orthopaedic care seems to be completed ease of treatment abroad, that is, with similar socio-cultural background of the neighbouring countries-particularly the border regions-of the Eastern-European region.
Of the reasons for choosing Hungary in treatment abroad better quality of care played a significant role and also friends' recommendations was noteworthy. Most of the patients still receive information from family and friends about having treatments abroad who have real-life experiences. The positive experiences of acquaintances might be spread through recommendations and facilitate patient mobility. Therefore, we can state that word-of-mouth is still a significant key driver in treatment abroad. However, future research is needed to explore more detailed features of cross-border care, e.g. changing key drivers, lack of care, quality of care and availability, accessibility in their home country.

Treatment of foreign patients is not a newly recognised phenomenon for Hungarian clinicians as they have already adapted to the situation over time, for instance by employing health professionals with other language skills. Based on the findings, patient mobility (mainly from Romania) to Hungary is noteworthy and increasing. The process is quite transparent and advantageous for Romanian patients while receiving better quality care and also for Hungarian clinics that might use their full capacities. Several studies investigated crossborder dental care in terms of Hungary, where Hungary is known as one of the main destination countries worldwide. Besides dental care, further specialties started contributing to cross-border care, such as orthopaedics. The broader significance of the present paper ensures opportunity to raise the awareness of existing patient mobility and positive patient experiences in other fields.

To conclude, the mobility flow of Romanian patients show the follows: since the prices do not differ the case of higher risk elective surgery in orthopaedics, the patients take the elevated risk of the long distance travelling and the challenges of crossborder healthcare due to the attraction of good quality of Hungarian orthopaedic traditions.

\section{Acknowledgements}

We are grateful to all the patients responding the survey and to all orthopaedic clinics providing the opportunity for conducting the research and particularly the heads of departments - Professor Zoltán Csernátony, Professor László Hangody, and Professor Kálmán Tóth; and Professor Endre Nagy for supporting the survey. Furthermore, we thank to all ECAB (Evaluating Care Across Borders) partners who contributed to the present research and the earlier versions of this paper, special thanks to Blanka Torok who conducted the follow-up interviews.

\author{
Ethical issues \\ The ECAB project was approved by the London School of Hygiene and Tropical \\ Medicine Ethics Committee.
}

\section{Competing interests}

We are not aware of any relationships or support which might be perceived as conflict of interest.

\section{Authors' contributions}

EK, GS, and CK were responsible for the concept and design of the study. EK and GS conducted the data collection, analysis and interpretation of data and prepared the draft of the manuscript. EK carried out the statistical analyses. 
GS And CK provided critical revision of the manuscript and supervision in the research.

Authors' affiliations

${ }^{1}$ Health Services Management Training Centre, Semmelweis University, Budapest, Hungary. ${ }^{2}$ Research Unit, Faculty of Public Health and Policy, London School of Hygiene and Tropical Medicine, London, UK

\section{References}

1. Sarah Caballero-Danell CM. Medical tourism and its entrepreneurial opportunities - A conceptual framework for entry into the industry [Master Dissertation]. Göteborg: Göteborg University; 2007.

2. Gallup Organization. Cross-border health services in the EU 2007. The Gallup Group; 2007.

3. Herrick DM. Medical tourism: Global competition in health care. National Center for Policy Analysis; 2007.

4. Horowitz MD, Rosensweig JA. Medical tourism--health care in the global economy. Physician Exec 2007; 33: 24-6

5. Lunt NS, Exworthy M, Green ST, Horsfall D, Mannion R. Medical Tourism: Treatments, markets and health system implications: $A$ scoping review. Paris: OECD; 2011.

6. Michalkó G, Rátz T, Hinek M. Spatial differences in Hungarian medical tourism supply based on service providers' online presence. Foldrajzi Ertesito/Hungarian Geographical Bulletin 2012; 61: 31-47.

7. Wismar M, Palm w, Figueras J, Ernst K, van Ginneken E. Cross-border health care in the European Union. Mapping and analysing practices and policies. Geneva: WHO; 2011.

8. Lunt N, Mannion R. Patient mobility in the global marketplace: a multidisciplinary perspective. Int J Health Policy Manag 2014; 2: 155-7. doi: 10.15171/ijhpm.2014.47

9. Connell J. Medical tourism. Wallingford: CABI; 2011.

10. McMahon D. Medical tourism and cross-border care. Background paper. Toronto: Nuffield Council on Bioethics; 2013.

11. Leahy $A L$. Medical tourism: the impact of travel to foreign countries for healthcare. Surgeon 2008; 5: 260-1. doi: 10.1016/ s1479-666x(08)80047-9

12. Lunt N, Carrera P. Medical tourism: Assessing the evidence on treatment abroad. Maturitas 2010; 66: 27-32. doi: 10.1016/j. maturitas.2010.01.017

13. Crooks VA, Kingsbury $P$, Snyder J, Johnston R. What is known about the patient's experience of medical tourism? A scoping review. BMC Health Ser Res 2010; 10: 266-78. doi:
10.1186/1472-6963-10-266

14. Smith M, Puczkó L. Health and wellness tourism. Netherlands: Elsevier/Butterworth-Heinemann; 2008.

15. Ruszinko A. Medical professions in health tourism, popular services. Hungary's Opportunities in the International Medical Tourism. Budapest, Hungary; 2010.

16. Cook PS. What is health and medical tourism? Annual Conference of the Australian Sociological Association. Victoria State, Melbourne; 2008

17. Reed CM. Medical Tourism. Med Clin North Am 2008; 92: 143346. doi: 10.1016/j.mcna.2008.08.001

18. Paulus A, Evers S, Fecher F, Van Der Made J, Boonen A. Cross border health care: An analysis of recent ECJ rulings. European Journal of Law and Economics 2002; 14: 61-73. doi: 10.1023/a:1015642601282

19. Legido-Quigley H, McKee M, Glinos I, Baeten R. Patient mobility in the European Union. BMJ 2007; 334: 188-90. doi: 10.1136/ bmj.39086.497639.68

20. Directive on the application of patients' rights in cross-border healthcare. 2011/24/EU (2011).

21. Hermesse J, Lewalle $\mathrm{H}$, Palm W. Patient mobility within the European Union: An introduction. Eur J Public Health 1997; 7 : 4-10. doi: 10.1093/eurpub/7.suppl 3.4

22. Kovacs E, Szocska G. Vacation for your teeth - Dental tourists in Hungary from the perspective of Hungarian dentists. J Dent Res 2013; 215: 415-8. doi: 10.1038/sj.bdj.2013.995

23. Wagner C, Moser F, Hohn A, Dobrick K, Verheyen F. EU CrossBorder Care Study 2012. Planned cross-border healthcare in the EU - Perspectives of TK insurees on doctors and dentists (Europabefragung 2012. Geplante grenzüberschreitende Versorgung in der EU - Ärzte und Zahnärzte aus Sicht der TKVersicherten). WINEG Wissen; 2013.

24. Klar A. Health tourism in Europe - An empirical cost-analysis (Gesundheitstourismus in Europa - Eine empirische Transaktionskosten-Analyse). Budapest: Andrássy Universität; 2013. p. 287.

25. Winkelmann J, Hofmarcher M, Kovacs E, Szocska G. Crossborder dental care between Austria and Hungary. Eurohealth 2013; 4: 26-8.

26. Knai C, Footman K, Glonti K, Warren E. The role of discharge summaries in improving continuity of care across borders. Eurohealth 2013; 4: 10-2. 


\section{Appendix 1}

\section{Patient Experience Survey}

1. Gender: 1. Male 2. Female

2. Age:

3. Country of origin:

4. What represents your social status: 1. Lower clas

5. What treatment have you arrived for? .

6. Do you combine treatments during your stay?
1. No, only one treatment
2. More than one treatment

7. Why did you choose Hungary?

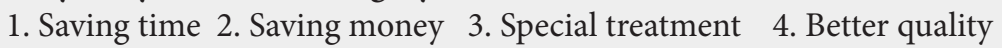

8. How did you plan your trip?
1. On my own
2. Medical tourism agency
3. Travel agency

9. Where did you get information about the treatment abroad? How did you find out about this hospital?

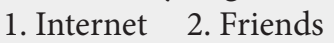
3. Newspaper, magazines
4. TV, radio ads 5. Doctors from home
6. Insurer

10. How easy was to get the appointment?
1. Not easy at all
2. Easy enough
3. Very easy

11. What would you say about the information provided?

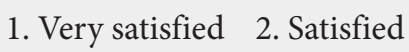
3. Not satisfied
4. Not satisfied at all

12. What is missing from existing information for patients? What are the main patient information needs?

13. Is it your first time having treatment abroad?

1. Yes 2. No, I had treatment abroad once 3. Several times

14. How long did you travel having this treatment? . $\mathrm{km}$

15. What do you think about the prices? Can you save?
1. Yes, I can save 2. No, prices are similar

16. What is the level of trust in foreign provider? 1 . High $\quad 2$. Medium $\quad 3$. Low

17. What kind of difficulties do you experience with the treatment abroad? 1. Misunderstanding 2. Sociocultural problems 3. Exhaustion 4. Extra expenses 5. None

18. What are the advantages of treatment abroad?

1. Improved quality 2. Higher accessibility 3 . Availability of special or joint treatments, aftercare

19. How satisfied are you with your process?

1. Very satisfied 2. Satisfied 3. Not satisfied 4. Not satisfied at all

20. How do you rate the communication with the health professionals?
$\begin{array}{ll}\text { 1. Excellent 2. Good 3. Poor } & \end{array}$

21. Do doctors here and your home country communicate with each other?
1. Yes
2. No

22. How different is the service here and your home country?

1. Not different 2. Similar, but better here 3. Similar, but better at home 4 . Very different

23. Do you receive a discharge summary or letter when you leave the hospital?
1. Yes 2. No

24. What language:
1. English
2. Hungarian
3. Romanian
4. Other:

25. Do you need a follow-up care?

1. No 2. Yes, aftercare provided in Hungary 3. Yes, aftercare provided in my home country 